\title{
The morphosyntax and morphothematics of voice
}

\author{
James P. Blevins \\ Journal of Language Sciences 24(4), 109-164
}

\section{Introduction}

The voice constructions of the world's languages appear to present a number of analytic challenges. A recurrent problem arises in distinguishing passives from constructions that exhibit overlapping formal and communicative properties. The diverse class of constructions that have been subsumed under an extended notion of 'passive' - including active impersonal constructions, evidential constructions, and even inverse constructions - testifies to the difficulties that arise in classifying voice constructions. At the same time, the relationship between passives and alternations that are formally similar to passives is obscured when the alternations show greater morphosyntactic variation than is exhibited by familiar promotional passives.

Nonetheless, a revealing classification of voice constructions can be obtained by rehabilitating traditional insights about the distinctive roles played by semantic and (morpho)syntactic factors. One traditional insight is that the passive alternation relates (i) a predicate that selects a 'logical' subject and (ii) a semantically detransitivized counterpart, in which the logical subject cannot be realized as a governed dependent (i.e., as a subject, object or indirect object). A second insight is that surface morphological patterns provide a more reliable guide to the grammatical function of dependents than classifications based on semantic roles, word order, etc.

The analysis of passive and inversion constructions outlined below illustrates the general applicability of the perspective expressed in traditional descriptive grammars and in parts of the Relational Grammar literature. Section 2 first presents a treatment of passive that develops the proposals in Comrie (1977) and Blevins (2003). Section 3 then sets out an account of the phenomenon of inversion in Georgian that develops the insights presented in traditional descriptions and in the Relational Grammar analyses of Harris $(1981,1984)$. A comparison of these analyses highlights the significant formal parallels between passive and inversion constructions and also suggests the usefulness of a generic model of Relation Grammar. 


\section{Passive constructions}

Personal passives are treated as 'the core case of passive' (Chomsky 1981) because they exhibit all or most of the properties associated with the passive construction. The German personal passive in (1b) illustrates some of these properties. The subject of the active clause in (1a) corresponds to the (optional) oblique dependent in (1b). The accusative direct object in (1a) corresponds to the subject in (1b), where it occurs in the nominative and triggers agreement on the finite auxiliary. On nearly all classifications of the prominence of grammatical relations, subjects are treated as more prominent than direct objects, which are regarded as more prominent than oblique dependents. On these assumptions, the logical subject in (la) is said to be 'demoted' to an oblique in (1b), whereas the logical object is 'promoted' to subject.

(1) a. Der Vorsitzender hat den Ausschuss aufgelöst. the.NOM chairman has the.ACC committee dissolved

'The chairman has dissolved the committee'.

b. Der Ausschuss wurde (von dem Vorsitzender) aufgelöst. the.NOM committee was by the.DAT chairman dissolved 'The committee was dissolved by the chairman.'

In formulating a general analysis of passive constructions, either of the two relational alternations: the 'demotion' of the logical subject, or the 'promotion' of the logical object, can be regarded as primary. On a demotional account, subject demotion is treated as the primary effect of passivization, and promotion as an opportunistic concomitant. On a promotional alternative, promotion is identified as the main effect of passivization, which induces the demotion of the logical subject.

Given that personal passives exhibit both demotion and promotion, they provide no basis for choosing between these alternatives. Subjectless passives like those in (2b) are of greater diagnostic value, since they exhibit subject demotion but show no evidence of promotion. As argued by Comrie (1977), a unified account of personal and subjectless passives can be defined in terms of subject demotion. In contrast, object promotion appears, at least prima facie, to be inapplicable in (2).

(2) a. Die Polizei haben bis spät in der Nacht verhandelt. the police have until late in the night negotiated 'The police negotiated until late in the night.'

b. Bis spät in der Nacht wurde (?von der Polizei) verhandelt. until late in the night was by the police negotiated 'There were negotiations until late in the night.' 
The passive counterparts of verbs that govern a dative complement define another class of subjectless passives in German. Examples like (3b) again exhibit demotion of the logical subject demotion in (3a). In contrast, there is no evidence of promotion, due to the fact that datives are not admissible subjects in German.

(3) a. Der Bürgermeister hat der Mannschaft gratuliert.

the.NOM mayor has the.DAT team congratulated

'The mayor congratulated the team.'

b. Der Mannschaft wurde (?von dem Bürgermeister) gratuliert.

the.DAT team was (by the mayor) congratulated

'The team was congratulated (by the mayor).'

\subsection{Passivization as thematic demotion}

Comrie's demotional treatment of the passive is formulated in a version of Relational Grammar (RG) that corresponds transparently to the accounts proposed in traditional grammatical descriptions. The basic intuition can be expressed in nearly any approach that distinguishes 'logical' and 'grammatical' levels of argument structure. In RG, both notions are encoded in terms of a set of grammatical relations, ranked according to the hierarchy in (4). Subjects, direct objects and indirect objects constitute the governable term relations; within this group, subjects and direct are distinguished as nuclear term relations. The class of oblique relations includes instrumentals, locatives and other dependents traditionally viewed as ungoverned.

(4) Grammatical relation hierarchy (cf. Perlmutter 1983) SUBJECT $>$ DIRECT OBJECT $>$ INDIRECT OBJECT $>$ OBLIQUE

A distinctive claim within RG is that dependents can be associated with grammatical relations at 'initial', 'final' and intermediate 'strata'. However, nearly every other model of argument structure confines grammatical relations to the 'final' or 'surface' level of analysis, and describes the 'initial' level in terms of semanticothematic participant roles. One conception of thematic argument structure follows in the tradition of Fillmore (1968) and Jackendoff (1972) and treats roles as discrete objects that are organized into a thematic hierarchy such as (5).

(5) Partial hierarchy of discrete roles agent $>$ benefactive $>$ goal $>$ patient

The proto-role proposal of Dowty (1991) provides the basis for an alternative conception, which is developed in a group of accounts (e.g., Ackerman 1992; Zaenen 1993; Alsina 1996; Ackerman and Moore 2001). On this approach, participant roles are regarded as clusters of Proto-Agent and Proto-Patient properties. In place of 
a hierarchically of discrete roles, these accounts introduce "an opposition between just two roles ... Proto-Agent and Proto-Patient" (Dowty 1991: 613) and correlate the rank of a role with the number of Proto-Agent properties that it contains.

In principle, a demotion analysis can be formulated equally well in terms of discrete roles or cluster concepts. The main requirement is just that there be some way of distinguishing the notion of 'logical subject'. In a model with discrete roles, logical subjects can be identified with the highest role in a thematic hierarchy, usually the agent, or possibly with all roles above a given threshold in the hierarchy. The binary classification imposed in proto-role approaches permits a simpler classification of a logical subject as the highest ranking Proto-Agent role. Given these conventions for representing argument structure, the default patterns of alignment exhibited by nuclear terms in the active constructions in (1a) and (2a) can be described as in Figure 1. Reflecting the prominence-preserving patterns of argument selection proposed in Dowty (1991), the Proto-Agent role $\mathrm{Ag}$ is associated with the grammatical subject sUBJ and the Proto-Patient (where present) with the grammatical direct object овJ.
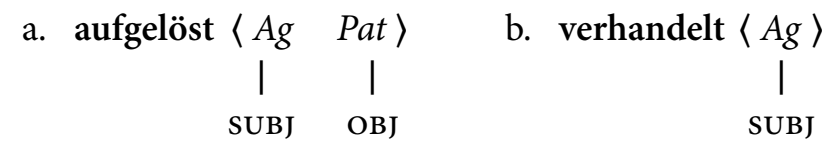

Figure 1: Active transitive and active intransitive argument structures

On the assumption that the logical subject is associated by default with the most prominent grammatical relation, any change in alignment will count as a demotion. However, demotion in the narrower sense that Comrie (1977) intends corresponds to the RG notion of chômage on which the logical subject is barred from an association with any term relation. The effect of this demotion is expressed in (6).

(6) Thematic Demotion

The passive alternation relates a predicate with a logical subject to a predicate in which the logical subject cannot be associated with a term relation.

Given that oblique relations tend to be optional, it is possible to express demotion in terms of an association to an oblique relation, as in Figure 2. This treatment of demotion represents a thematic counterpart of the initial LFG account of Bresnan (1982b), on which a suBJ function was mapped onto an OBL function. Alternatively, the notion of demotion as chômage can be expressed directly as a constraint against associating the logical subject with any term relation, as in Figure 3. As with syntactic representations in general, these schematizations are useful to the extent that 
Figure 2: Thematic Demotion as oblique association

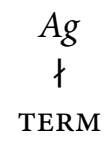

Figure 3: Thematic Demotion as term dissociation

they clarify the effect of passivization. Both both inhibit the association of a logical subject with a grammatical term relation and neither refers to logical objects.

The effect of this inhibition is reflected in the passive argument structures in Figure 4, corresponding to the examples in (1b) and (2b). As a consequence of the-

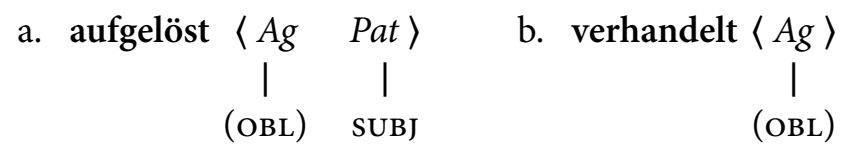

Figure 4: Personal and subjectless passive argument structures

matic demotion, the only association possible for the logical subject $\mathrm{Ag}$ in Figure 4 is with an (optional) oblique relation. This demotion in turn induces the 'promotion' or 'advancement' of the logical object Pat in Figure 4a. On a demotional analysis, promotion makes no specific reference to passive constructions but instead reflects the same general principle that associates the highest role with the highest available grammatical relation in active constructions. In Figure 4a, the logical object Pat is the highest role that is eligible to associate with term relations, and the grammatical subject sUвJ is the highest available term relation.

\subsection{The Unaccusative Hypothesis}

A striking feature of Comrie's subject-oriented analysis is how straightforwardly it interacts with the primary valence contrast recognized in RG. The Unaccusative Hypothesis (UH) distinguishes predicates like VerHANDELN 'negotiate' in (2) from predicates like BLEIBEN 'remain' in (7) in terms of their initial argument structure. 
As formulated in Perlmutter and Postal (1983a: 69), the UH holds that 'many intransitive clauses have an initial direct object but no subject'. Such clauses, termed 'initially unaccusative', contrast with 'initially unergative' clauses, which do contain an initial subject. If, as suggested above, 'clauses that contain initial subjects' are represented as predicates that specify a logical subject proto-role $A g$, the agentive verb RAUCHEN 'smoke' will be classified as unergative. The 'initial object' associated with verbs like BLEIBEN will likewise correspond a logical object proto-role Pat, determining an unaccusative classification. A demotional analysis of passivization interacts with this contrast to account for the observation that unaccusative verbs do not passivize. The unacceptability of unaccusative passive in (7b) illustrates this restriction.

(7) a. Die Polizei sind bis spät in der Nacht geblieben. the police are until late in the night remained 'The police remained until late in the night.'

b. ${ }^{\star}$ Bis spät in der Nacht wurde (von der Polizei) geblieben. until late in the night was by the police remained 'There was remaining until late in the night.'

A demotional analysis that targets logical subjects is intrinsically sensitive to the variation in argument structure posited by the UH. If passivization demotes logical subjects, it will fail to apply to verbs without logical subjects, as in Figure 5. More

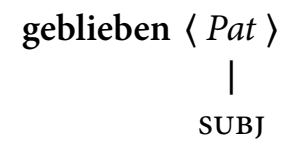

Figure 5: Active argument structure of unaccusative intransitive

generally, it follows directly that ' $[n]$ o impersonal Passive clause in any language can be based on an unaccusative predicate' (Perlmutter and Postal 1984:107). Of course to avoid circularity the classification of unergative and unaccusative predicates must be determinable independently of their susceptibility to passivization.

Despite the simplicity of this account, Comrie's reformulation of a traditional account of passivization met with fierce resistance within RG, as it entailed a treatment of the passive in which demotion of the logical subject occurred 'spontaneously', rather than as a consequence of an antecedent promotion. Orthodox models of RG standardized instead on alternatives in which subjectless passives involved advancement of a demotion-inducing 'dummy' nominal and valence constraints on passivization were attributed to a variety of 'laws', notably the Motivated Chômage Law and the '1-Advancement Exclusiveness Law' (Perlmutter and Postal 1984: 84). 
Of arguably greater contemporary relevance are questions about the role that the typological properties of familiar Indo-European languages played in reinforcing the primacy of personal passives and in supporting the intuition that all passives were (at some level of analysis) promotional. The recognition of these assumptions as typological artifacts permits the restoration of an elegant analysis of passive constructions in terms that are broadly compatible with the subtantive claims of RG.

\subsection{Impersonal and evidential constructions}

Similar questions about the effects of typological bias arise in a more acute form in connection with claims about 'passives of unaccusatives' and 'double passives'. $\mathrm{Pu}$ tative cases of this type are presented as counterevidence to the UH in a variety of accounts including Timberlake (1982), Baker et al. (1989) and Bresnan and Kanerva (1989). Yet an examination of extant cases suggests that they are all spurious. The ubiquity of passive constructions in Western Indo-European languages has created a pervasive descriptive bias. A 'passive' analysis is frequently extended to constructions that occupy a similar communicative niche (constructions that are 'passive in meaning'), as well as to constructions that incorporate elements that have an etymological connection to genuine passives (constructions that are residually 'passive in form'). Unsurprisingly, constructions that are merely 'passive in meaning or form' do not obey the constraints proposed for genuine passive constructions.

As suggested in Blevins (2003) and argued at length in a number of more detailed studies, the constructions that have sometimes been identified as allowing the passivization of unaccusative predicates are predominantly active impersonals (Shore 1988; Tommola 1997; Kibort 2003; Torn-Leesik 2016) or evidentials (Spraunienè et al. 2015). Cases of double passives likewise reflect the interaction of a range of voice and mood processes. If passivation is involved at all, it applies to an initially unergative predicate and produces a semantically detransitivized output that may satisfy the requirements for subsequent impersonal or evidential processes.

These studies support the view that there can be no characterization of languages that permit unaccusative and double passives, because, as claimed in RG accounts, there are no such languages. However, the reasoning is more streamlined on a demotional treatment of the passive. There are no passives of unaccusatives because passivization demotes logical subjects, and the lack of a logical subject is what defines unaccusatives as a class. There are no double passives, because passivization defines a derived unaccusative, and unaccusatives, again, do not passivize. 


\section{Thematic inversion in Georgian}

A demotional analysis of passivization also brings out significant parallels with the inversion construction in Georgian, in which canonical patterns of case and agreement marking appear to be 'inverted'. The clause in (8a) exhibits the Future pattern, in which the subject st'udent'i occurs in the nominative, and is indexed by the subject agreement suffix $-s .{ }^{1}$ The indirect object amxanags occurs in what is traditionally termed the 'dative' case, and is indexed by the indirect object agreement prefix $s$-. The direct object c'erils is also dative (there is no distinct accusative case in Georgian), but is not indexed on the verb. The Perfect clause in (8b) inverts the marking of logical arguments. The logical subject, st'udent's, is dative and co-occurs with the prefix $u$-, which is the form of the Perfect 'version vowel' $i$ - that encodes the selection of an indirect object. The logical direct object c'erili occurs in the nominative, and is indexed by the subject agreement suffix $-a$. The logical indirect object amxanagis is unindexed and occurs in the genitive case governed by the postposition $t v i s$.

(8) Case and agreement inversion in Georgian (Tschenkéli 1958: 499)

a. St'udent'i misc'ers amxanags c'erils. student.NOM 3IO.write.3su comrade.DAT letter.DAT

'The student will write a letter to his comrade.'

b. St'udent's miuc'eris amxanagis-tvis c'erili. student.DAT 3IO.write.3SU comrade.GEN-for letter.NOM

'The student has (apparently) written a letter to his comrade.'

Capturing the correspondence between the direct and inversion constructions in (8) raises questions about the organization of the Georgian grammatical system that in turn present challenges to current models of morphosyntax. This section addresses three principal challenges. The first and most fundamental challenge arises in explicating the principles that account for the observation that the logical subject st'udent's in (8b) exhibits the same case and agreement properties as the indirect object amxanags in (8a), while the logical object c'erili in (8b) patterns with the subject in (8a). The second challenge arises in characterizing the constraints on verbs that participate in inversion and, in particular, in accounting for the fact that unaccusative verbs do not exhibit inversion. The third challenge arises in accounting for the properties of other dependents in inversion constructions, notably the fact that logical indirect objects must be realized as postpositional obliques.

\footnotetext{
${ }^{1}$ Example glosses identify relevant properties of forms, and suppress preverbs, version vowels and other morphological details. Case is indicated by the labels NOM 'nominative' DAT 'dative', ERG 'ergative' and GEN 'genitive'. Agreement glosses are composed of the person values 1, 2, 3 and the abbreviations su 'subject', Do 'direct object' and Io 'indirect object'.
} 
There are two dominant strategies for expressing the correspondence between direct and inversion constructions, each with accompanying assumptions about the factors that constrain the choice of verbs and the form of dependents. A traditional approach is outlined in Tschenkéli (1958) and developed in greater detail in Harris $(1981,1984)$ and Tuite (1998). On this view, inversion disrupts the default, prominence-preserving association between 'logical' (or 'initial') argument structure and 'surface' grammatical relations by expressing the logical subject as a surface indirect object. Given this analysis of the dative nominal in inversion constructions, case and agreement patterns can be keyed uniformly to surface grammatical relations, in inversion just as in direct constructions. The fact that logical indirect objects must be realized as postpositional arguments can be attributed to the fact that an inversion construction already contains a surface indirect object.

The alternative proposed in Anderson $(1984,1992)$ and Aronson (1990) expresses a fundamentally different intuition. This analysis locates inversion in the relation between surface grammatical relations and inflectional properties. On this view, inversion represents a 'quirky' valence pattern in which the surface subject is marked dative and indexed by agreement markers that are normally associated with indirect objects, and the object occurs in the nominative and is indexed by agreement markers that otherwise encode properties of the syntactic subject. The principal appeal of this account comes from the thematic uniformity of subjects and direct objects. Logical subjects are consistently realized as surface subjects, whether they occur in the nominative in direct constructions or in the dative in inversion constructions. Logical direct objects show the same consistency, whether they occur in the dative in direct constructions or in the nominative in inversion construction. Yet thematic uniformity does not extend to indirect objects. Although logical indirect objects are realized as dative-marked grammatical indirect objects in direct constructions, they can only be realized as postpositional objects in inversion constructions.

It might appear that traditional and quirky valence analyses both stipulate the idiosyncratic properties of inversion constructions but at different grammatical levels. Whereas a traditional analysis assigns a construction-specific mapping between participant roles and grammatical relations, the alternative specifies exceptional case and agreement features. Some constraints, notably the restrictions on the verbs that participate in inversion, can be incorporated within either type of account. Specifically, unaccusative verbs will be excluded from inversion constructions if inversion is formulated as a rule that targets logical subjects (Harris 1981), as in the passive constructions above. However, differences between these accounts emerge when their effects on the Georgian grammatical system as a whole are taken into account. A traditional analysis introduces a single construction-specific association between logical subjects and indirect objects, from which most of the properties of inversion constructions follow, directly or indirectly. In contrast, a thematically 
uniform analysis significantly complicates the morphosyntactic system by introducing a novel valence pattern with idiosyncratic case and agreement properties.

This core difference reflects a more basic disagreement about the organization of the Georgian conjugational system. A quirky valence approach associates each of the three inflectional series in Georgian with a distinctive valence pattern. The first (Future/Present) series is associated with the nominative-dative pattern in (8a). This direct pattern is taken to be inverted in the third (Perfect/Evidential) series, which exhibits the dative-nominative pattern in (8b). The second (Aorist) series introduces yet another distinctive pattern, which is illustrated in (9). In this series, logical subjects are realized as 'ergative' (or 'narrative') subjects and trigger subject agreement, while logical direct objects occur as nominative objects, unindexed for agreement. Logical indirect objects are realized as dative indirect objects and trigger indirect object agreement.

(9) Case and agreement in the Aorist series (Tschenkéli 1958: 499)

St'udent'ma misc'era amxanags c'erili.

student.ERG 3IO.write.3su comrade.DAT letter.NOM

'The student wrote a letter to his comrade.'

From a traditional perspective, there are only two morphosyntactic patterns in Georgian. The examples in (8) both conform to a nominative-dative pattern, in which nominative is associated with the highest grammatical relation (the subject) and dative is associated with direct and indirect objects. The Aorist pattern in (9) disrupts this pattern by associating the grammatical subject with ergative case, leaving nominative to be associated with the highest remaining grammatical relation, which is now the direct object. Grammatical indirect objects are marked dative, as they are in all series in which they can occur. Overall, there is a default nominativedative valence pattern that interacts thematically with the demotion of the logical subject in the Perfect series and grammatically with the distinctive ergative marking of grammatical subjects in the Aorist series.

\subsection{Thematic inversion}

The present subsection sets out the benefits of a traditional account in more detail. As noted above, treating the logical subject in an inversion construction as a surface indirect object accounts immediately for the case and agreement properties of the dative and nominative arguments. This analysis assimilates the morphosyntactic properties of the Perfect construction in (8b) to the Future pattern in (8a) by maintaining a uniform association between surface grammatical relations and case and 
agreement properties. ${ }^{2}$ In both constructions, nominative arguments are syntactic subjects, indexed by subject agreement markers. Dative arguments are syntactic objects or indirect objects, indexed by objective agreement markers.

Treating the logical subject as a grammatical indirect object also contributes to an account of the form of the other arguments in inversion constructions. In constructions with a logical direct object, the 'demotion' of the logical subject induces the 'promotion' of the logical object to the status of a surface subject, again mirroring the pattern in passives. Hence the logical objects c'rili 'letter' in the ditransitive (8b) and surati 'picture' in transitive (10b) both surface with the case and agreement properties appropriate to a surface subject.

(10) Future and Perfect transitives (Tschenkéli 1958: 498)

a. Mxat'vari daxat'avs surats. painter.NOM 3DO.paint.3SU picture.DAT

'The painter will paint a picture.'

b. Mxat'vars dauxat'avs surati.

painter.DAT 3IO.paint.3su picture.NOM

'The painter (apparently) has painted a picture.'

Treating the dative argument as an indirect object also offers an explanation for the selective detransitivizing effect of inversion. As examples (10) and (11) show, inversion does not invariably reduce the number of grammatical relations that are directly governed by a verb. The logical subject and object in the transitive Future construction in (10a) are also expressed as verbal dependents in the corresponding Perfect construction in (10b), albeit with the characteristic 'inversion' of case and agreement properties. The logical subject of the 'absolute' intransitive CEK'vA 'dance is likewise realized as nominative Merabi in the Present construction in (11a), and as the dative dependent Merabs in the Perfect in (11b). ${ }^{3}$

(11) Present and Perfect 'absolute' intransitives (Harris 1981: 135f.)

a. Merabi cek'vavs.

Merab.Nom dance.3su

'Merab is dancing.'

b. Merabs ucek'via.

Merab.DAT 3IO.dance.3su

'Merab apparently (has) danced.'

\footnotetext{
${ }^{2}$ The analyses of Georgian in Wunderlich (1997) and Joppen-Hellwig (2001) adopt a similarly direct mapping between grammatical relations and morphological properties.

${ }^{3}$ Following traditional descriptions, the term 'transitive' is reserved for verbs that govern a direct object. Intransitive verbs are divided into two classes: 'absolute' verbs, which just govern a subject, and 'relative' verbs, which also select an indirect object.
} 
Yet, as discussed above, a logical indirect object cannot be realized as a direct verbal dependent in inversion constructions. This restriction is illustrated by the form of the 'goal' dependents in (8) and (12). In the ditransitive Future clause in (8a), the logical indirect object amxanags is realized as a dative verbal dependent, which is indexed on the verb. The non-subject dependent p'ropesors in the intransitive Present clause in (12a) also occurs in the dative and is again indexed on the verb. But in the corresponding Perfect clauses, both dependents are obligatorily realized as postpositional objects, which do not trigger verbal agreement. In (8b), amxanagis occurs as the genitive argument of $t v i$ ' 'for', whereas in (12b), p'ropesor occurs as the dative argument of tan 'to'.

(12) Present and Perfect 'relative' intransitives (Tschenkéli 1958: 604)

a. St'udent'i elap'arakeba p'ropesors. student.NOM 3IO.speak.3su professor.DAT

'The student is speaking with the professor.'

b. St'udent's ulap'arakia p'ropesor-tan. student.DAT 3IO.speak.3SU professor.DAT-to

'The student has (apparently) spoken with the professor.'

The evident generalization is that logical indirect objects cannot surface as indirect objects in inversion constructions. This restriction cannot be attributed to general case, agreement or thematic constraints. Georgian freely allows multiple dative dependents in uninverted ditransitive clauses like (8a). Ditransitive verbs also permit dative dependents to remain unindexed. In ditransitive constructions, the verb agrees with the dative goal argument, which corresponds to an indirect object, and the dative theme argument corresponding to a traditional direct object remains unindexed. There is also no sense in which the agentive roles associated with the demoted logical subjects of the inversion constructions in (8b)-(12b) conflict with the goal or recipient roles associated with the logical indirect objects in (8) and (12). Rather, the operative constraint appears to apply to surface grammatical relations: a verb that governs an indirect object in direct constructions cannot realize the corresponding dependent as an indirect object in inversion constructions.

As Harris (1981) argues, a traditional analysis offers a natural account of this restriction, given a principle - such as Stratal Uniqueness (Perlmutter and Postal 1977) - which independently allows at most one surface indirect object. If the logical subject is realized as a grammatical indirect object in inversion constructions, it follows that no other argument will also be able to surface as an indirect object. The logical indirect object must then be expressed as a more oblique dependent, which in Georgian takes the form of an object of a postposition such as tvis or tan. Two aspects of this explanation require further elaboration to forestall possible misinterpretation. 
First, it does not ultimately matter whether the dependent in question is classified as a traditional 'indirect object', as a '3-relation' (Perlmutter and Postal 1977), as an 'ОВ 2' (Bresnan 1982a), as a 'secondary object' (Dryer 1986), or in other terms. What is critical is just that this dependent is syntactically distinct from subjects and direct objects, and is not merely a thematically restricted subclass of objects, as in later LFG accounts (Bresnan et al. 2016). Second, the observation that Stratal Uniqueness is as relevant to indirect objects as it is to subjects and direct objects in Georgian does not imply that a similar constraint must apply in all languages, or even that all languages contain indirect objects. There are languages in which indirect objects do not appear to be motivated, either because they are absent altogether or because they can be characterized in terms of case marking (Alsina 1996) or thematic status (Bresnan and Zaenen 1990) within a larger class of objects. However, these patterns do not undermine the relevance of indirect objects in languages, such as Georgian, where these objects play a central syntactic role.

An analysis that associates logical subjects with grammatical indirect objects also offers a principled account for restrictions on participating verb types. If inversion targets logical subjects, it should not apply to verbs that lack logical subjects, just as in the passive constructions discussed in Section 2. Thus there is a clear expectation that unaccusative verbs should again not occur in inversion constructions. Georgian grammars conventionally recognize a class of 'passive' verbs, containing passives, inchoatives and other types of unaccusatives. Example (13a) illustrates one type of true passive, corresponding to the active transitive in (10a).

(13) Future and Perfect 'absolute' passives (Tschenkéli 1958: 254/577)

a. Surati ixat'eba.

painting.NOM paint.3sU

'The picture will be painted.'

b. Surati uk've daxat'uliq'o

painting.NOM already paint.3su

'The picture (apparently) has been painted.'

Passive verbs have full conjugational paradigms, which include evidential Perfect forms such as daxat'uliq'o in (13b). However, as Harris (1981) observes, Perfect constructions containing unaccusative verbs do not exhibit case and agreement inversion. In both the Present (13a) and the Future (13b), the logical object surati 'picture' surfaces as a nominative grammatical subject. Unaccusatives with indirect objects show a similar pattern. As in (13), the logical object masc'avlebeli 'teacher' surfaces as a nominative grammatical subject in the Present and Perfect constructions in (14). Moreover, in contrast to the Perfect constructions in (8b) and (11b), the logical indirect object moc'apes 'pupil' in (14b) surfaces as a grammatical indirect 
object, which is marked dative and triggers indirect object agreement on the verb.

(14) Present and Perfect 'relative' unaccusatives (Tschenkéli 1958: 579)

a. Masc'avlebeli udzavrdeba moc'apes. teacher.NOM 3IO.angers.3su pupil.DAT 'The teacher grows angry at the pupil.'

b. Masc'avlebeli gasdzavrebia moc'apes. teacher.NOM 3IO.angers.3SU pupil.DAT

'The teacher (apparently) has grown angry at the pupil.'

Voice alternations in other verb classes confirm the role of logical subjects. Georgian contains a class of 'indirect' or 'affective' verbs, which exhibit inversion throughout their entire conjugational paradigm. This is shown in the Present construction in (15a), where the logical subject of $s d u l s$ 'hates' is realized as a dative indirect object and the logical object as a nominative surface subject. Yet as Harris $(1981,139)$ notes, the passive counterparts of indirect verbs do not exhibit inversion. Instead, as (15b) illustrates, the logical objects of indirect passives surface as grammatical subjects, as happens with other unaccusatives.

(15) Present and Passive 'indirect' verbs (Harris 1981:139)

a. Vanos sdzuls direkt'ori.

Vano.DAT 3IO.hate.3su director.NOM

'Vano hates the director.'

b. Direkt'ori šedzulebulia.

teacher.NOM hate.3su

'The director is hated.'

In sum, treating inversion as a non-canonical mapping between logical arguments and surface grammatical relations offers a natural account of the form of inversion constructions and the restrictions on inversion. ${ }^{4}$

\subsection{The conjugational system of Georgian}

An overview of the conjugational system of Georgian further clarifies how a demotional treatment of inversion conforms to general morphosyntactic patterns within the language. The system is defined in large part by four conjugations (Aronson 1990) or classes (Harris 1981) and three basic inflectional series. Although the conjugations are true form classes, defined in terms of Future and Aorist principal parts

\footnotetext{
${ }^{4}$ Harris (1981) provides additional support for a traditional analysis, based on a range of phenomena, including 'Object Camouflage', which is discussed in more detail in Section 3.5.3.
} 
((Harris 1981: 260); Blevins (2006: \$4)) it is more informative to refer to conjugations in terms of the associated valence classes in Table 1. The first conjugation consists mainly of transitive verbs. The second 'passive' conjugation contains mostly unaccusative intransitives, which are often derived from first conjugation transitives. The third 'medial' conjugation mainly contains unergative intransitives. The fourth 'indirect' conjugation consists of verbs that exhibit thematic inversion in all series.

\begin{tabular}{clll}
\hline Conjugation & Valence Class & \multicolumn{2}{c}{ Example } \\
\hline 1 & Transitive & daxat'avs & 's/he will paint it' \\
2 & Unaccusative & darčeba & 's/he will remain' \\
3 & Unergative & icek'vebs & 's/he will dance' \\
4 & Indirect & mosc'ons & 's/he likes it' \\
\hline
\end{tabular}

Table 1: Georgian verb classes (cf. Tschenkéli (1958: 63); Harris (1981: 16))

The inflectional series contain sets of paradigms, traditionally termed screeves. It is again more mnemonic to refer to these series by their tense/aspect properties than by the usual Roman numerals I, II and III. The Present series (Series I) consists of subseries that contain present and future screeves. The Aorist series (Series II) contains aorist screeves, and the Perfect/Evidential series (Series III) contains inverted screeves(i.e. screeves that exhibit inversion), which are residually perfect in form but usually evidential in meaning. The basic organization of series and screeves is summarized in Table $2 .^{5}$

\begin{tabular}{cllll}
\hline Series & 'Tense' & Nonpast & Past & Subjunctive \\
\hline I & Present & Present Indicative & Imperfect & Conjunctive Present \\
I & Future & Future Indicative & Conditional & Conjunctive Future \\
II & Aorist & \multicolumn{2}{c}{ Aorist Indicative } & Optative \\
III & Perfect & Present perfect & & Pluperfect \\
\hline
\end{tabular}

Table 2: Classification of Georgian screeves (Aronson 1990: 462)

\footnotetext{
${ }^{5}$ This classification departs from Aronson (1990) in substituting 'subjunctive' for his label 'modal' and in treating the present perfect as a nonpast rather than as a past screeve.
} 


\subsubsection{Valence patterns}

Each tense/aspect series is associated with distinctive patterns of agreement and case government. The patterns exhibited by transitive and unergative verbs in the Aorist and Present series are shown in (16).

(16) Direct unergative patterns (Tschenkéli 1958: 499)

a. St'udent'ma misc'era amxanags c'erili. student.ERG 3IO.write.3su comrade.DAT letter.NOM

'The student wrote a letter to his comrade.'

b. St'udent'i misc'ers amxanags c'erils. student.NOM 3IO.write.3su comrade.DAT letter.DAT

'The student is writing a letter to his comrade.'

Example (16a) illustrates pattern 'A', which is characteristic of the Aorist series. In this pattern, the grammatical subject occurs in the ergative, the object occurs in the nominative, and the indirect object occurs in the dative. Example (16b), repeated from (8a), exhibits pattern 'B', which is associated with the Present series. In this pattern, the grammatical subject is nominative, and the object and indirect object are both dative. Both patterns exhibit a 'direct' (i.e. non-inverted) correspondence between logical arguments and surface grammatical relations, and a direct relation between surface relations and case patterns, as summarized in Table 3.

\begin{tabular}{cccc}
\hline & Subject & Object & Indirect Object \\
\hline A & ERG & NOM & DAT \\
B & NOM & DAT & DAT \\
\hline
\end{tabular}

Table 3: Direct valence patterns in Georgian

One should not read too much into the traditional case labels 'ergative' and 'dative' in Table 3. As Tschenkéli (1958:2) remarks, "the so-called ergative" is "also named the active or narrative". Hence the use of the case label 'ergative' does not imply that ergative arguments enter into an ergative/absolutive opposition (Anderson 1992), rather than an active/inactive opposition (Harris 1981, 1985). Tschenkéli's use of the term 'dative/accusative' for the case that is often glossed simply as 'dative' likewise underscores the fact that there is no distinct accusative form in Georgian, so that the dative may mark direct as well as indirect objects.

Unaccusative verbs exhibit a slightly different association with the patterns in Table 3. In the present series, unaccusative verbs, like their unergative counterparts, 
follow pattern B. This is shown by the Present form ec'ereba in (17b), which selects a nominative subject and a dative indirect object. In the Aorist series, unaccusatives differ markedly from their unergative counterparts. Whereas unergative (and transitive) verbs follow pattern A in the Aorist series, unaccusatives again follow pattern B. Hence the Aorist form miec'era in (17a) selects a nominative subject, which differs from the ergative subject selected by miscera in (16a) and thereby neutralizes the contrast with the subject of the Present unaccusative in (17b).

(17) Direct unaccusative patterns (Tschenkéli 1958: 404)

a. C'erili miec'era p'ropesors. letter.NOM 3IO.written.3sU professor.DAT

'The letter was written to the professor.'

b. C'erili ec'ereba p'ropesors. letter.NOM 3IO.written.3su professor.DAT 'The letter is (being) written to the professor.'

Unaccusatives also conform to pattern B in the Perfect series, as illustrated by the examples in (18), which are repeated from (13b) and (14b). Although Perfect forms of unaccusative verbs carry the same evidential meaning as unaccusatives, they govern nominative subjects and dative indirect objects. Hence in all series, unaccusatives conform to pattern $B$.

(18) Perfect 'absolute' and 'relative' passives (Tschenkéli 1958: 577)

a. Surati uk've daxat'uliq'o painting.NOM already paint.3su

'The picture (apparently) has been painted.'

b. Masc'avlebeli gasdzavrebia moc'apes. teacher.NOM 3IO.angers.3SU pupil.DAT

'The teacher (apparently) has grown angry at the pupil.'

In direct constructions, agreement, like case, is conditioned by surface grammatical relations. To avoid prejudging the analysis of inversion constructions, agreement markers are described in Table 4 using the form-based terms in Tuite (1998) and Anderson (1992). ${ }^{6}$ The $v$-and $m$-sets are each identified by their 1 sg marker and the $h$-set by its 3 sg marker.

As summarized in Table 5, v-set markers index ergative subjects in pattern A, and the nominative subjects in pattern $\mathrm{B}$. The $m$-set markers index the nominative object in pattern $\mathrm{A}$ and the dative direct object in pattern $\mathrm{B}$. The $h$-set markers index dative indirect objects in both patterns.

\footnotetext{
${ }^{6}$ The dashes in Table 4 represent verb stems, commas separate morphologically conditioned alternants, and slashes separate phonologically conditioned variants.
} 


\begin{tabular}{llll}
\hline & $v$-set & $m$-set & $h$-set \\
\hline 1 sg & $\mathrm{v}-$ & $\mathrm{m}-$ & $\mathrm{m}-$ \\
$1 \mathrm{pl}$ & $\mathrm{v}-\mathrm{t}$ & $\mathrm{gv}-$ & $\mathrm{gv}-$ \\
$2 \mathrm{sg}$ & - & $\mathrm{g}-$ & $\mathrm{g}-$ \\
$2 \mathrm{pl}$ & $-\mathrm{t}$ & $\mathrm{g}-\mathrm{t}$ & $\mathrm{g}-\mathrm{t}$ \\
$3 \mathrm{sg}$ & $-\mathrm{s}, \mathrm{a}, \mathrm{o}$ & - & $\mathrm{h} / \mathrm{s}-$ \\
$3 \mathrm{pl}$ & $-\mathrm{an} / \mathrm{en}, \mathrm{es}$, nen & - & $\mathrm{h} / \mathrm{s}-$ \\
\hline
\end{tabular}

Table 4: Basic agreement marker sets

\begin{tabular}{cccc}
\hline & $v$-set & $m$-set & $h$-set \\
\hline A & ERG & NOM & DAT \\
B & NOM & DAT & DAT \\
\hline
\end{tabular}

Table 5: Direct case and agreement correlations

\subsection{The locus of Inversion}

Inversion arises in two places in the conjugational system of Georgian. In the Perfect series of transitive and unergative verbs, logical subjects occur in the dative and condition $h$-set agreement. The logical objects of transitive verbs occur in the nominative and condition $v$-set agreement. Logical indirect objects cannot be realized as direct verbal arguments and must be expressed by postpositional phrases. Each of these properties is illustrated in (19a), repeated from (8b). The class of 'indirect'verbs, which express psychological states and modal meanings, also exhibit inversion. Yet, unlike transitive and unergative verbs, indirect verbs exhibit inversion in all series, as illustrated by the inverted Present construction in (19b).

(19) Inversion constructions (Tschenkéli 1958: 499/449)

a. St'udent's miuc'eris amxanagis-tvis c'erili. student.DAT 3IO.write.3SU comrade.GEN-for letter.NOM 'The student has (apparently) written a letter to his comrade.'

b. Mamas uq'vars švili.

Father.DAT 3IO.love.3su child.NOM

'The father loves the child.'

Inversion constructions clearly disrupt the canonical association between logical arguments and morphosyntactic case and agreement properties. The primary 
analytical choice concerns the locus of this inversion; whether it occurs (i) in the mapping from logical to surface argument structure, or (ii) in the association between surface arguments and morphosyntactic processes.

\subsubsection{Morphosyntactic inversion}

On the second alternative, inversion exhibits a 'quirky' valence pattern ' $C$ ', in which "the grammatical subject ... is in the dative case" and "the object is in the nominative" (Aronson 1990: 333). This analysis maintains a uniform mapping between logical arguments and grammatical relations, since the logical subject is consistently realized as a surface subject and the logical object as a grammatical direct object. However, as Table 6 shows, pattern $\mathrm{C}$ disrupts the relation between surface argument structure and morphosyntactic properties in a highly pattern-specific way.

\begin{tabular}{lllllll}
\hline & \multicolumn{2}{c}{ Subject } & \multicolumn{2}{c}{ Object } & \multicolumn{2}{c}{ Indirect Object } \\
\hline A & ERG & $v$-set & NOM & $m$-set & DAT & $h$-set \\
B & NOM & $v$-set & DAT & $m$-set & DAT & $h$-set \\
C & DAT & $h$-set & NOM & $v$-set & \multicolumn{2}{c}{-} \\
\hline & \multicolumn{2}{ll}{ Logical Subject } & \multicolumn{2}{l}{ Logical Object } & Logical Indirect Object \\
\hline
\end{tabular}

Table 6: Quirky valence (Aronson (1990: 333); (Anderson 1992: 145))

Dative subjects that trigger $h$-set agreement are unique to pattern C, as are nominative direct objects that trigger $v$-set agreement. The recognition of a new valence pattern also offers no principled explanation for the fact that the logical indirect object cannot be realized as a grammatical indirect object in pattern C. If the dative argument is treated as subject or, at any rate, as something other than an indirect object, there is no evident motivation for the demotion of the logical indirect object, given that pattern $\mathrm{B}$ permits multiple datives. Because each argument in pattern $\mathrm{C}$ differs from corresponding arguments in $\mathrm{A}$ and $\mathrm{B}$, there is no way to assimilate $\mathrm{C}$ to either of the other patterns. Hence a quirky valence analysis of inversion introduces a third basic pattern into the morphological system in Table 7.

In short, quirky valence maintains thematic uniformity at the cost of recognizing a third morphological pattern that is distinct in fundamental respects from patterns $A$ and B. It is a matter of execution whether these differences are expressed directly, by pattern-specific rules, or indirectly, for example, by means of disjunctive case and agreement rules that apply to structured morphosyntactic representations with expedient empty layers, along the lines suggested by Anderson (1992, 153ff.). In 


\begin{tabular}{ccccc}
\hline & Transitive & Unaccusative & Unergative & Indirect \\
\hline Present & $\mathrm{B}$ & $\mathrm{B}$ & $\mathrm{B}$ & $\mathrm{C}$ \\
Aorist & $\mathrm{A}$ & $\mathrm{B}$ & $\mathrm{A}$ & $\mathrm{C}$ \\
Perfect & $\mathrm{C}$ & $\mathrm{B}$ & $\mathrm{C}$ & $\mathrm{C}$ \\
\hline
\end{tabular}

Table 7: Correlations between patterns, series and conjugations

either case, the postulation of morphosyntactic inversion significantly complicates the description of the case and agreement system of Georgian.

\subsubsection{Thematic inversion}

A traditional analysis proceeds from the observation that there are at most two distinct morphological patterns in Georgian. Correlating case and agreement, as in Table 8, identifies the case-agreement correspondence in pattern $\mathrm{C}$ as a subcase of the pattern $\mathrm{B}$ correspondence. Pattern $\mathrm{C}$ can then be fully assimilated to pattern $\mathrm{B}$ if, as in a traditional account, the nominative is treated as a grammatical subject and the dative as an indirect object.

\begin{tabular}{cccc}
\hline & Subject & Object & Indirect Object \\
\hline & $v$-set & $m$-set & $h$-set \\
A & ERG & NOM & DAT \\
B & NOM & DAT & DAT \\
$(\mathrm{C})$ & NOM & - & DAT \\
\hline
\end{tabular}

Table 8: Traditional grammatical analyses (Tschenkéli 1958; Harris 1981)

The analysis in Table 8 highlights the close relation between grammatical relations and case and agreement properties established by a traditional account. Ergative case is associated with subjects in pattern $\mathrm{A}$, and dative case is associated with indirect objects in general. Nominative is associated with the highest available 'nuclear term' (Perlmutter and Postal 1983b: 86). The relation between agreement markers and surface grammatical relations is even more direct. The $v$-set markers index grammatical subjects, the $m$-set markers index direct objects and the $h$-set markers index indirect objects. This correspondence is indeed so direct that one can dispense entirely with the designations ' $v$-set', ' $m$-set' and ' $h$-set' markers in favour of the more informative terms 'subject', 'object' and 'indirect object' markers, which 
are adopted in Tschenkéli (1958), Harris (1981), Aronson (1990) and Hewitt (1995).

More generally, a traditional account brings out the morpho-thematic basis of patterns that appear arbitrary on a quirky valence account. On the analysis in Table 8 , the distinction between patterns $\mathrm{B}$ and $\mathrm{C}$ are purely morpho-thematic. In direct constructions conforming to pattern $B$, the logical subject is realized as a surface subject. In the inverted constructions that are assigned to pattern $\mathrm{C}$, the logical subject is realized as an indirect object. Given this contrast, the other differences between patterns $\mathrm{B}$ and $\mathrm{C}$ follow from general morphosyntactic conventions.

Assimilating pattern $\mathrm{C}$ to pattern $\mathrm{B}$ also identifies the 'morpho-thematic' basis of the contrast between patterns $A$ and $B$. As Table 9 shows, the alternation between pattern $A$ and the general pattern $B$ is confined to the Aorist series. Like the varia-

\begin{tabular}{ccccc}
\hline & Transitive & Unaccusative & Unergative & Indirect \\
\hline Present & $\mathrm{B}$ & $\mathrm{B}$ & $\mathrm{B}$ & $\mathrm{B}$ \\
Aorist & $\mathrm{A}$ & $\mathrm{B}$ & $\mathrm{A}$ & $\mathrm{B}$ \\
Perfect & $\mathrm{B}$ & $\mathrm{B}$ & $\mathrm{B}$ & $\mathrm{B}$ \\
\hline
\end{tabular}

Table 9: Revised correspondences between series and classes

tion between patterns $\mathrm{B}$ and $\mathrm{C}$, the alternation between $\mathrm{A}$ and $\mathrm{B}$ correlates with the realization of logical subjects. Harris (1981:244) expresses the correlation between argument structure and case marking in the Aorist series associating ergative case with grammatical subjects that correspond to initial (or, in present terms, logical) subjects. Transitive and unergative verbs both select logical subjects that surface as grammatical subjects, so these subjects are marked ergative. Unaccusative verbs lack logical subjects altogether, and the logical subjects of indirect verbs are realized as indirect objects. So the grammatical subjects of unaccusative and indirect verbs occur in the nominative, in accordance with the default case marking conventions in Georgian.

\subsection{Inversion as demotion}

The preceding discussion identifies the motivation for a traditional analysis that treats the dative nominal in an inversion construction as an indirect object. On this account, there is one set of general case and agreement conventions, correlated with surface grammatical relations, and two types of thematically-conditioned deviations. There is, in particular, one set of basic agreement conventions and a default pattern of case marking. The resulting description simplifies individual morphosyntactic patterns in Georgian while bringing out the organization of the whole system. 
The present section now outlines how a correspondence-based model captures and extends the insights of traditional analyses. The contribution of this type of model lies partly in the factorization that it offers. Defining 'logical' argument structure in thematic terms expresses the central role that semantic properties play in guiding argument realization. The level of 'surface' grammatical relations is likewise the natural locus of syntactic and morphosyntactic phenomena, such as agreement and case government. The division of grammatical labour between levels is largely attributable to intrinsic differences between the types of elements that comprise each level, rather than to constraints that stipulate which kinds of phenomena are conditioned by elements at different levels or strata. This factorization permits a more detailed treatment of case and agreement patterns than in traditional or in RG accounts, while highlighting parallels with formally similar constructions.

\subsubsection{Relational demotion}

As with passivization, the principal challenge for a traditional account lies in characterizing the levels of 'logical' and 'grammatical' argument structure and in specifying the principles that associate these levels. The account in Harris (1981) construes logical and grammatical arguments in terms of initial and final grammatical relations proposed within RG. Logical arguments are represented at the initial stratum of a relational network, where a logical subject bears a ' 1 ' (subject) relation, a logical direct object bears an initial ' 2 ' (object) relation and a logical indirect object bears an initial ' 3 ' (indirect object) relation. The relations assigned in the final stratum of a network represent the surface argument structure that mainly conditions case and agreement patterns. Harris formulates the inversion rule as a process that demotes an initial subject to a final indirect object, and attributes the promotion of the object to an independent rule of Unaccusative Advancement:

According to this hypothesis, Inversion is a single process:

c. Inversion Subject $\rightarrow$ Indirect Object.

The initial indirect object is put en chômage, according to the Chômeur Condition. The direct object advances to subject, by Unaccusative Advancement. Inversion proper is just the process of a subject becoming an indirect object. (Harris 1981: 247)

Figure 6: Inversion as a rule of grammar

To account for the fact that unaccusative verbs do not undergo inversion, Harris restricts the application of inversion to initial subjects. 
(20) The Initial Subject Constraint on Inversion (Harris 1981:247)

Inversion applies only to initial subjects

A relational demotion analysis captures the insights of traditional accounts and extends these accounts by offering general explanations for patterns of advancement, and for restrictions on the application of the inversion rule. The main objection to this analysis presented by proponents of the thematically uniform alternative objects that relational demotion treats inversion structures as "reflect[ing] an actual change in syntactic structure" (Anderson 1992: 153). Harris' analysis is open to this objection because of the fact that the each of the strata in a relational network are classified as syntactic in orthodox RG models. However, it is important to recognize that this is in large part a meta-criticism, which is directed more at a derivational interpretation of RG than at the specific treatment of inversion in Harris (1981). It is of course true that RG was developed as a derivational syntactic model and that Harris (1981) adopts this perspective. But, at the same time, it must be acknowledged that RG analyses tend to make fairly minimal reference to constituency, word order or other features of syntactic 'arrangement', in the sense of Bloomfield (1933). Hence many of the patterns of promotion and demotion within RG analyses correspond to (and can be reinterpreted as) lexical alternations, in which strata correspond to different aspects or dimensions of the argument structure of a predicate.

This point is particularly relevant to the analysis of inversion in Harris (1981). The relational networks in this analysis contain almost no information about the form or arrangement of syntactic dependents, and mainly express alternations in the patterns of government or argument selection associated with verbs belonging to different lexical classes and inflectional series. The treatment of these alternations does not depend in any fundamental way on the idea that inversion "reflects an actual change in syntactic structure". Instead, only the final stratum of grammatical relations in a relational network need be regarded as syntactic, since this is the level at which grammatical relation assignments interact with surface syntactic properties. The properties represented at earlier strata can then be classified as part of the lexico-thematic argument structure of the main predicate in a relational network.

A second object is that, by disrupting the canonical association between logical arguments and syntactic functions, traditional accounts sacrifice the thematic uniformity of analyses that treat inversion as a quirky valence pattern. On thematically uniform analyses, logical subjects are consistently realized as surface subjects in all constructions, inverted as well as direct. Hence the thematic properties that are taken to define logical subjects can be used to identify grammatical subjects. Yet thematic uniformity is not a property that would necessarily be expected to hold across constructions, particularly constructions that exhibit a contrast between the declarative mood of direct forms and evidential mood associated with inversion. 
Moreover, few of the distinctive grammatical properties of inversion constructions follow from quirky valence analyses. Classifying logical subjects as dative-marked subjects provides no basis for the selective detransitivizing effect of inversion. As the examples in Section 3.1 show, a logical indirect object can surface as a dative argument in a ditransitive construction with a dative direct object, or in an inversion construction with a nominative subject. It is only when the logical subject is realized with the case and agreement properties of an indirect object that the logical indirect object must be expressed as a postpositional object. A quirky valence analysis can of course restrict inversion to verbs that select logical subjects, as in a traditional account. But imposing this restriction produces an analysis on which logical subjects, however they are distinguished, are mapped onto grammatical subjects with the form and agreement properties of indirect objects in the Perfect series.

\subsubsection{Thematic demotion}

Consequently, the objections to an analysis based on relational demotion can be met by recasting the central insights of a traditional analysis in terms of thematic demotion within a correspondence-based approach to argument structure. As with the passive alternation, the process of inversion can be expressed in nearly any approach that distinguishes 'logical' and 'grammatical' levels of argument structure. One could reformulate the analysis of inversion within a correspondence-based version of RG, along the lines suggested in Blevins (2003). Some, though not all, prerequisites of this analysis are also present in the approaches to argument structure developed within lexicalist frameworks, as discussed in Section 4.1 below.

However, the model of argument structure proposed in the analysis of passivation in Section 2 permits a similarly transparent formulation of inversion. Georgian inversion is a canonical demotion, as it disrupts a default pattern of realization that would preserve the prominence of a logical argument. Like passivization, it singles out the logical subject for demotion. Yet unlike passivization, which inhibits an association between the the logical subject and any term relation, inversion associates the logical subject with the non-nuclear term ІОВJ, as represented in Figure $7 .{ }^{7}$

The effect of inversion is shown by the contrast between the direct structure assigned with the Future construction (10a) in Figure 8a, and the inverted structure assigned to the Perfect (10b) in Figure 8b. In Figure 8a, the logical subject $A g$ is associated with the sUBJ relation and the logical object $P a t$ with the овJ, again reflecting the default patterns of argument selection in Dowty (1991). In Figure 8b, the inversion rule associates the logical subject with the indirect object говј. This

\footnotetext{
${ }^{7} \mathrm{~A}$ counterpart of the dissociative passive analysis in Figure 3 is also possible. On this account inversion inhibits an association between the logical subject and a nuclear term relation, so that the association with an indirect object reflects the default association with the highest available relation.
} 


\section{$A g$ \\ I \\ IOBJ}

Figure 7: Thematic Inversion
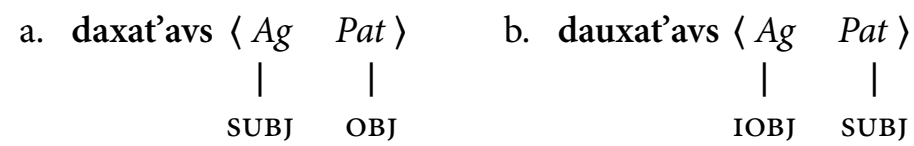

Figure 8: Future and Perfect transitive structures

demotion induces the promotion of the logical object to an association with the highest available relation, the grammatical subject, suBJ.

As in the analysis of passivization in Section 2, inversion represents a systematic deviation from default patterns of argument realization. The alternation between direct and inverted patterns can be characterized entirely with respect to the argument structure of individual predicates, so there no sense in which inversion involves an notion of "syntactic restructuring" (Anderson 1992: 153).

\subsubsection{Argument realization in Georgian}

In order to extend this analysis to the full range of patterns summarized above, it is necessary to specify argument structures in slightly greater detail. There are two basic approaches to correspondence-based models of argument structure. A direct approach defines a native prominence ranking on each of the levels of analysis and specifies principles that relate elements at different levels. Models of RG, Headdriven Phrase Structure Grammar (Manning and Sag 1999) and many of the initial role-based accounts adopt versions of this strategy. A more indirect approach defines a native order on one level, usually the thematic level, and then projects that order by associating features or other properties with roles. This strategy is best exemplified by models of Lexical Mapping Theory within LFG (Bresnan et al. 2016). There is often a fairly transparent correspondence between the components of these models, down to the level of argument classification. The intertranslatability between RG and LFG classifications is illustrated in Table 10; the only substantive point of disagreement concerns the status of indirect objects, as discussed in Section 4.1.

The principles that map between levels in correspondence-based models tend to preserve thematic prominence, just as relational networks preserve grammatical relation assignments across strata by default. The one systematic exception involves 


\begin{tabular}{cccccc}
\hline & Term & Nuclear Term & Objective Relation & r(estricted) & o(bjective) \\
\hline sUвј & $\checkmark$ & $\checkmark$ & $x$ & - & - \\
ОВЈ & $\checkmark$ & $\checkmark$ & $\checkmark$ & - & + \\
ІОВЈ/овј $\theta$ & $\checkmark$ & $x$ & $\checkmark$ & + & + \\
ОвL & $x$ & $x$ & $x$ & + & - \\
\hline
\end{tabular}

Table 10: Correspondences between RG and LMT classifications

indirect objects. Logical indirect objects are relatively prominent thematically, in Dowty's (1991) terms containing more Proto-Agent properties than logical direct objects interpreted as patients or themes. Yet, in Georgian as in many languages, logical indirect objects are realized as the non-nuclear term говј. This mismatch, represented in Figure 9, captures the intuition underlying the notion of a '2-3 retreat' in RG (Perlmutter and Postal 1983b:105) while locating the alternation in the mapping from logical to grammatical levels of argument structure. Given the general intertranslatability of analysis, it is useful to adopt a relatively generic description of argument structure that largely abstracts away from theory-dependent assumptions and highlights properties of Georgian inversion constructions.

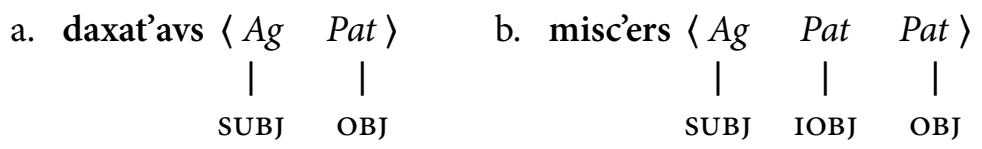

Figure 9: Default transitive and ditransitive alignment

\subsubsection{Inversion}

The inverted counterparts of the structures in Figure 9 are given in Figure 10.
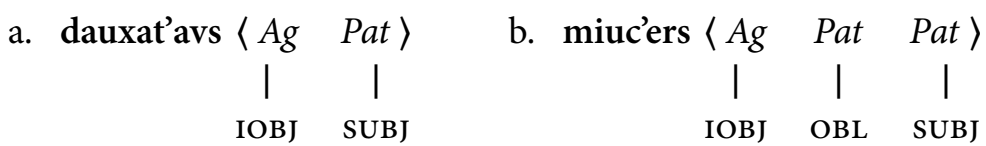

Figure 10: Inverted transitive and ditransitive alignment

The promotion of the logical direct objects to associations with grammatical 
SUBJ relations in Figure 10 follows the same pattern as passives. However, the demotion of the logical indirect object in Figure 10b exhibits distinctive properties of inversion constructions. The default association with the grammatical IOBJ is disrupted by the inversion rule, which maps the logical subject onto the говJ relation. No other IOВJ relation is available on the assumption that, in Georgian at least, relations are unique at the grammatical level of an argument structure. This assumption falls under the Stratal Uniqueness Law in RG (Perlmutter and Postal 1983b: 92). ${ }^{8}$

The explanation for the observation that the logical indirect object cannot be promoted to an association with a grammatical direct object shows the greatest theory-dependency. In RG accounts, the logical indirect object will be an an initial IOBJ, and the final association of the logical subject with IOBJ will place the logical indirect object en chômage, precluding reassociation with any term relation. In LMT, the logical indirect object will be specified as $[+r]$, which bars association with a $[-r]$ овј (though not with a $[+r] \mathrm{OBJ}_{\theta}$ ). A generic version of this condition would key the incompatibility between logical indirect objects and grammatical oBJ relations in inversion to the same properties (e.g., Proto-Agent properties) that determine the association with grammatical ІовJs rather than овJs in direct constructions.

The lack of an available term relation leaves only the option of oblique realization for the logical indirect object. Since oblique relations are expressed as postpositional dependents in Georgian, the logical indirect object is expressed with tvis 'for' in (8b).

In sum, the contrast between the Present structures in Figure 9 and the Perfect counterparts in Figure 10 shows how inversion disrupts the default realization of the logical arguments. The demotion of the logical subject to a grammatical Іовј induces the advancement of the logical object to grammatical suBJ and forces the logical indirect object to be realized as an optional postpositional oblique. The structures in Figure 11, corresponding to the Present and Perfect unergatives in (12), exhibit a parallel pattern. The Proto-Patient in Figure 11 is again classified as logical indirect object (or as a restricted role). This classification ensures that it is realized as a grammatical ІовJ, not as an object, in the direct example in (12a)/Figure 11a, and as an OBL relations, not as a grammatical suBJ, in (12b)/Figure 11b.
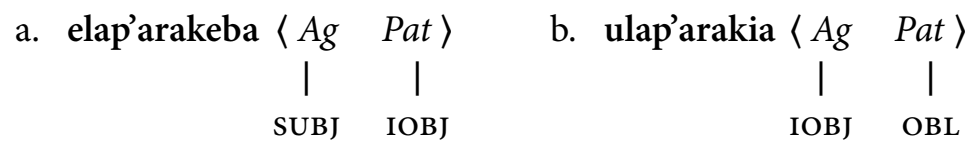

Figure 11: Direct and inverted argument realization in unergatives

\footnotetext{
${ }^{8}$ It would also be covered by the Function-Argument Biuniqueness condition in LFG (Bresnan 2001: 311) if indirect objects were treated on a par with subjects and direct objects.
} 
The inverted structures in Figure 10 and Figure 11b explicate the detransitivizing effect of inversion. Following the demotion of the logical subject, the logical object must advance, to be realized as the grammatical subject. But the logical indirect object can neither advance, to be realized as the grammatical object, nor surface as an indirect object. Hence an inverted verb governs one fewer grammatical relations than a direct counterpart. In unergative verbs, inversion leads to a surface structure with an indirect object and an optional postpositional dependent. However, the structures of Perfect unergative verbs contain no grammatical subject, in violation of the Final 1 Law of RG and the Subject Condition of LFG. ${ }^{9}$

Indirect verbs exhibit a similar pattern of inverted argument realization, but in all series, suggesting that an inverted argument structure is a lexically property of this class of predicates. As the Present form in (21a) shows, logically transitive indirect verbs pattern with Perfect forms of transitive verbs. The Present form in (21b) likewise shows that logically intransitive indirect verbs pattern with Perfect forms of unergatives.

(21) Inversion in the Present series of indirect verbs (Harris 1981: 139/136)

a. Vanos sdzuls direkt'ori.

Vano.DAT 3Io.hate.3Su director.NOM

'Vano hates the director.'

b. Bavšvs uxaria. child.DAT 3Io.be-happy.3su.

'The child is happy'.

In the structure assigned to sduls 'hates' in Figure 12a, the logical subject is realized as a grammatical гов and the logical object as a grammatical suвJ, just as in the structure for dauxat'avs in Figure 10. The structure of intransitive uxaria 'is happy' in Figure 12b contains just a grammatical IOBJ and, like the structures of Perfect unergatives, lacks a grammatical suBJ.

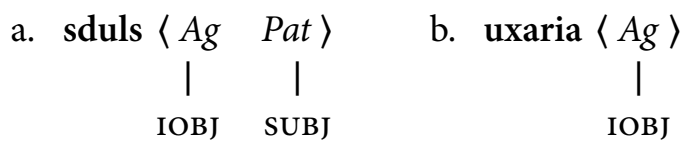

Figure 12: Argument realization in Present indirect verbs

Indirect verbs bring out the central difference between the use of discrete roles such as agent, patient, goal, etc., and the use of cluster concepts such as Proto-Agent

\footnotetext{
${ }^{9}$ Though, as argued in Blevins (2003), these constraints just appear to reflect typological biases.
} 
and Proto-Patient. An inversion rule that targets agent roles would not normally be expected to apply to the logical subjects of verbs like 'be happy' or 'love', which are not canonical agents. In contrast, a rule that targets Proto-Agents would be expected to apply to indirect verbs because the logical subjects of indirect verbs will qualify as Proto-Agents on nearly all standard definitions. Although these roles do not exercise volitional control over the event or state denoted by an indirect verb, they are associated with other Proto-Agent properties, such as sentience and existence independent of the event. Hence, the logical subjects of indirect verbs will be characterized as Proto-Agents, irrespective of whether Proto-Agents are defined as participant roles (i) with more Proto-Agent properties than Proto-Patient properties (Dowty 1991), (ii) with more "heavily weighted" Proto-Agent than Proto-Patient properties (Ackerman 1992), or even (iii) with a distinguished Proto-Agent property, such as sentience. ${ }^{10}$

\subsubsection{Unaccusativity}

Treating inversion as a process that targets logical subjects offers an explanation for the fact that unaccusative verbs do not exhibit inversion. The 'objectlike' character of the arguments of unaccusatives can be expressed in terms of proto-roles, discrete roles, initial relational assignments, or in terms of the $[-r]$ features assigned to patient-like roles in LMT accounts. However, following Dowty (1991), the argument structure of unaccusatives are distinguished by the fact that they contain only Proto-Patient roles, as in the analysis of unaccusatives in Section 2.2. Given that the inversion rule in Figure 7 demotes Proto-Agents, it will fail to apply to unaccusatives, so that argument realization in Perfect unaccusatives will exhibit the same default patterns as in the corresponding Present constructions. The structures in Figure 13 first illustrate the pattern in 'absolute' unaccusatives, exemplified by (13) above, which do not select an indirect object. In the structure for Future ixat'eba 'will paint' in Figure 13a, the Proto-Patient role is realized as the grammatical suBJ, due again to the pattern expressed by Unaccusative Advancement. Because inversion applies only to verbs that select a Proto-Agent, the Proto-Patient is also realized as the grammatical subj in the structure for Perfect daxat'uliq'o in Figure 13b.

The structures in Figure 14 exhibit a similar pattern in 'relative' unaccusatives, exemplified by (14) above, which govern an indirect object. The structure for Present

\footnotetext{
${ }^{10} \mathrm{An}$ analysis based on discrete roles can express the same distinction by introducing a 'cognizer' role between the agent and the next-highest role on the thematic hierarchy. The inversion rule can then apply to all roles above this thematic threshold, for example, to all roles that are more prominent than benefactive in the hierarchy in (5). On both alternatives, the inversion rule targets roles that are associated with all Proto-Agent properties except volitionality, though an analysis based on discrete roles expresses this generalization by reifying a partial bundle of proto-properties as a participant role.
} 


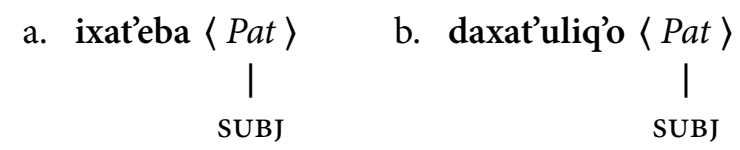

Figure 13: Argument realization in absolute unaccusatives

udzavrdeba 'grows angry' in Figure 14a realizes the most prominent Proto-Patient role as the grammatical suBj and the restricted Proto-Patient role as a grammatical iobj. Because inversion again does not apply, argument realization in the structure of Perfect gasdzavrebia in Figure 14b preserves the default pattern.

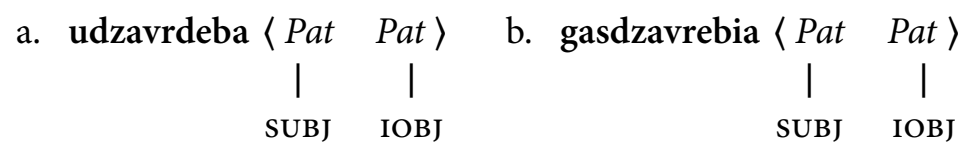

Figure 14: Argument realization in relative unaccusatives

An inversion rule that targets logical subjects will also capture the alternation between indirect verbs and their passive counterparts. The structure for Present sduls 'hates' in Figure 15a contains a Proto-Agent that meets the prerequisites of the inversion rule. But since the structure for the corresponding passive šedzulebulia in Figure 15b contains only a Proto-Patient, it cannot undergo inversion. Instead, like other unaccusative predicates, passives of indirect verbs exhibit the default pattern of argument realization.

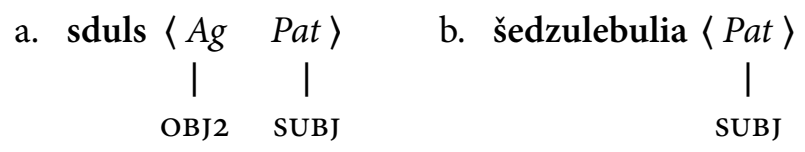

Figure 15: Argument realization in Present indirect verbs

\subsection{Valence patterns}

Isolating inversion in the mapping from logical to surface arguments provides a stable grammatical locus for morphosyntactic properties. As discussed in Section 3.3, a thematic treatment of inversion highlights the simple opposition between the valence patterns A and B in Table 11. The morphosyntactic properties that define these valence patterns derive in turn from general case and agreement principles, which 


\begin{tabular}{cccc}
\hline & SUBJ & OBJ & OBJ2 \\
\hline & $v$-set & $m$-set & $h$-set \\
A & ERG & NOM & DAT \\
B & NOM & DAT & DAT \\
\hline
\end{tabular}

Table 11: Valence patterns (Tschenkéli 1958; Harris 1981)

are largely keyed to surface grammatical relations. The case conventions are summarized in Section 3.5.1 and the basic agreement properties in Section 3.5.2.

\subsubsection{Case}

The case alternations in Table 11 reflect the interaction of two patterns. By default, nominative case is associated with the highest grammatical relation (subject or object) in an argument structure. However, this general pattern is disrupted by more specific constraints on the case of subjects in the Aorist series and objects in the Present series. The interactions are described below by a general nominative constraint, (22a), which is overridden by more function-specific constraints on the ergative and dative. The constraint in (22b) expresses the insight that the case traditionally termed 'ergative' marks final subjects that correspond to an initial subject in the Aorist series (Harris 1981, 1985). This is precisely the type of bistratal relation that can be expressed in terms of the thematic and grammatical levels. The constraint in (22c) ensures that nominative is only assigned to the highest unrestricted relation by associating dative with direct objects that co-occur with a nominative subject. The constraint in (22d) represents the fact that indirect objects always occur in the dative, irrespective of the marking of other arguments.

\section{(22) Case Constraints}

a. Nominative is associated with a nuclear term/unrestricted relation.

b. Ergative is associated with a SUBJ that realizes a Proto-Agent in the Aorist.

c. Dative is associated with an овJ in a structure with a nominative sUвJ.

d. Dative is associated with an IовJ.

The case patterns described by these principles are summarized in Tables 16 and 17. This description uses the LMT features as mnemonics for classifying roles but similar distinctions could be expressed in terms of the RG classification in Table 10. The unergative pattern, represented by the 3sg Present form cek'vavs 'to dance' is given in Table 16a. In the Present series, the nominative subject conforms to the default in (22a). In the Aorist series, the ergative subject falls under (22b), which 


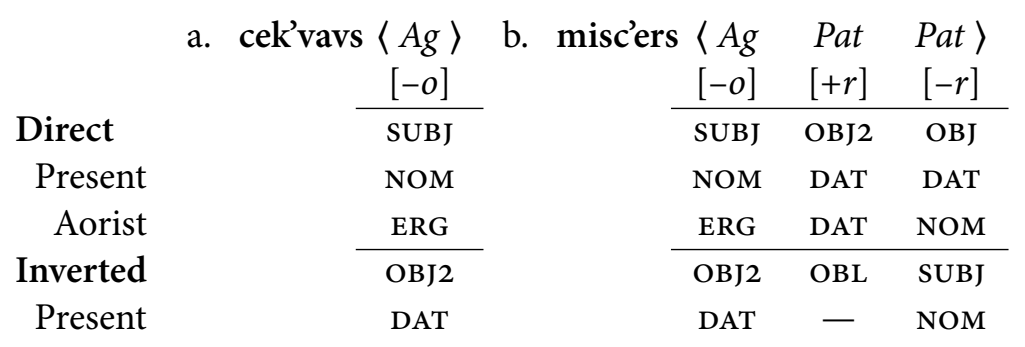

Figure 16: Case marking with unergative and transitive verbs

associates a Proto-Agentive subject with ergative case. ${ }^{11}$ The dative indirect object in the Perfect series conforms to (22d), which associates all indirect objects with the dative. The ditransitive pattern, represented by the $3 \mathrm{sg}$ Present form of 'to write' misc'ers is shown in Table 16b. The case of grammatical subjects dictates the case of direct objects. If the subject is ergative, the object is nominative, in accordance with (22a). If the subject is nominative, the object is dative, in conformance with (22b).

The distinctive property of the unaccusative structures in Figure 17 is the preservation of a default association between case and grammatical relations in all series. The passive 'be painted', represented by the Future form ixat'eba in Figure 17a, uniformly governs the nominative because its sole thematic role is a Proto-Patient, which cannot be realized by an ergative subject in the Aorist series, nor as a dative indirect object in the Perfect. The inchoative 'grow angry', represented by the Present $u d z a v r d e b a$ in Figure 17b, similarly governs a nominative subject and dative indirect object in all series.

\begin{tabular}{ccccc} 
& a. ixat'eba $\langle$ Pat $\rangle$ & b. udzavrdeba $\langle$ Pat & Pat $\rangle$ \\
& SUB & & {$[-r]$} & {$[+r]$} \\
\cline { 2 - 4 } Direct & SUBJ & SUBJ & OBJ2 \\
Present & NOM & NOM & DAT \\
Aorist & NOM & NOM & DAT \\
Perfect & NOM & NOM & DAT
\end{tabular}

Figure 17: Uniform case marking in unaccusative verbs

\footnotetext{
${ }^{11}$ The association of 'ergative' case with subjects of intransitives indicates that it does not participate in any kind of standard ergative/absolutive opposition. Instead, as Harris $(1981,1985)$ argues at length, the ergative marking of subjects in the Aorist series identifies the active members in a case opposition of the active/inactive type.
} 


\subsubsection{Agreement}

There is an even more transparent relation between agreement properties and surface grammatical relations. As shown in Section 3.3.2, v-set markers encode subject properties, $m$-set markers encode object properties and $h$-set markers encode the properties of indirect objects. The correlation between agreement properties and grammatical relations can be clarified further if $m$-set markers are associated with objective relations, as in (23c).

\section{(23) Realization of agreement properties}

a. $v$-set markers realize properties of a SUBJ.

b. $h$-set markers realize properties of an говј.

c. $m$-set markers realize properties of an objective $([+o])$ relation.

The agreement principles in (23) eliminate much of the redundancy between the $m$-set and $h$-set markers in Table 4 and bring out more clearly the structure of the agreement system. As the revised chart in Table 18 indicates, there is only one set of indirect object prefixes, $h / s$, and no distinctive direct object markers. The apparent homophony between the $m$-set and $h$-set markers in Table 4 reflects the fact that each of the 'pairs' realize the agreement properties of the most thematically prominent objective relation. The $m$-set markers realize the properties of indirect object, if one is present, otherwise the properties of a direct object, as Tschenkéli (1958:368) notes in remarking that "in verbs with 2 objects only a single objective person marker can appear, which serves exclusively to express the indirect object".

\begin{tabular}{llll}
\hline & sUв & {$[+o]$} & ІОВј \\
\hline $1 s g$ & $\mathrm{v}-$ & $\mathrm{m}-$ & \\
$1 \mathrm{pl}$ & $\mathrm{v}-\mathrm{t}$ & $\mathrm{gv}-$ & \\
$2 \mathrm{sg}$ & & $\mathrm{g}-$ & \\
$2 \mathrm{pl}$ & $-\mathrm{t}$ & $\mathrm{g}-\mathrm{t}$ & \\
$3 \mathrm{sg}$ & $-\mathrm{s}, \mathrm{a}, \mathrm{o}$ & & $\mathrm{h} / \mathrm{s}-$ \\
$3 \mathrm{pl}$ & $-\mathrm{an} / \mathrm{en}, \mathrm{es}, \mathrm{nen}$ & & $\mathrm{h} / \mathrm{s}-$ \\
\hline
\end{tabular}

Figure 18: Revised agreement marker sets

The description in Table 18 summarizes only the basic agreement patterns in Georgian, and does not distinguish the realization of person from number features or address complications due to animacy (Harris 1985; Tuite 1998) or 'competition' between markers (Anderson 1992; Stump 2001). These refinements are mostly orthogonal to the association between agreement and argument structure, though it 
is worth clarifying one source of systematic ambiguity. As indicated by the position of markers relative to the stem ' -' in Table 18, there are two main agreement 'slots' in the Georgian verb: a pre-radical slot that predominantly marks object properties and a post-radical slot that predominantly marks subject agreement properties. The lack of a pre-radical marker identifies third person objects or indirect objects of transitive verbs and correlates with the absence of an object with intransitives. The lack of a post-radical marker identifies verbs with second person subjects, irrespective of transitivity. Hence, subjectless verbs - such as the Perfect forms of unergatives - do not occur without a post-radical marker, but instead take a formally third person singular marker. Although this pattern is sometimes described in terms of agreement with a 'dummy' element (Anderson 1992:155), it reflects a relatively familiar case of systematic ambiguity, in which third singular forms alternate between encoding the properties of a third person agreement controller and encoding the absence of an agreement relation (Jakobson 1932; Blevins 2000).

\subsubsection{Object Camouflage}

The observation that agreement is triggered by the most thematically prominent objective relation also suggests an account of the phenomenon of 'Object Camouflage’ described in (Harris 1981: \$3). In Georgian, a ditransitive verb cannot govern an indirect object together with a first or second person direct object. To express this combination, the first or second person object must be represented as a third person object, which contains a first or second person possessive pronoun and (the appropriate form of) the noun TAVI 'self'. This phenomenon is illustrated in (24).

(24) Object Camouflage in Georgian (Harris 1984:265)

a. ${ }^{\star D e d a ~(s ̌ e n) ~ g a b a r e b s ~ m a s c ' a v l e b e l s . ~}$ mother.NOM YOu.DAT 2OB.renders.3su teacher.DAT

('Mother is turning you over to the teacher.')

b. Deda abarebs masc'avlebels šens tavs. mother.NOM 3IO.renders.3su teacher.DAT your self.DAT

'Mother is turning you over to the teacher.'

Examples such as (8a) above show that a ditransitive verb can govern two third person objects. Example (24a) suggests that a second person direct object cannot be indexed on a ditransitive verb by the agreement marker $g$-, irrespective of whether the object pronoun, here šen, is overtly expressed or not. Example (24b) indicates that the intended meaning of (24a) can be conveyed by 'camouflaging' the second person object as a possessive pronoun within the third person object šens tavs. Because third person direct objects are not overtly indexed on a verb, the form adarebs is compatible with the two third person objects in (24b). 
Camouflaging first and second person objects as third person forms provides an intriguing solution to a problem created by the interaction of morphosyntactic principles and morphological structure in Georgian. The most general principle is that the agreement marking of a finite verb in Georgian must be compatible with any grammatical relation directly governed by the verb. A more language-specific principle is that agreement with a more thematically prominent indirect object takes priority over agreement with a less syntactically marked direct object. ${ }^{12}$ The need to assign priority arises because ditransitive verbs in Georgian have more arguments than agreement 'slots'. A camouflaging solution to this mismatch exploits the fact that third person direct objects are not indexed on the verb.

The interaction of Object Camouflage and inversion also lends a measure of support to an analysis of the type outlined above. As (Harris 1981:142) notes, "Object Camouflage never applies with inversion predicates" irrespective of whether the inversion is triggered by Perfect forms or with indirect verbs. The pattern in inversion verbs is illustrated in (25).

(25) Lack of Camouflage with Indirect Verbs (Harris 1981: 142)

a. (me) momc'ons pelamuši.

me.DAT 1Io.like.3su pelamushi.NOM

'I like pelamushi (a food).'

b. čems tavs moscons pelamuši.

my self.DAT 1Io.like.3su pelamushi.NOM

('I like pelamushi')

The lack of Object Camouflage in (25) requires no special explanation. In (25a), the first person indirect object $m e$ is indexed by the first person $m$-set marker $m$-, while the subject pelamuši is indexed by the third person $v$-set marker $-s$. There is no direct object to index on the verb - and, indeed, there cannot be, given the detransitivizing effect of inversion. Since there is no mismatch between arguments and agreement slots, there is motivation for camouflaging a complement of a ditransitive verb as a third person form in an inversion construction. Hence the camouflaged alternative in (25b) is unacceptable. The fact that nominative arguments in inversion constructions do not undergo Object Camouflage in the presence of an agentive indirect object also supports the traditional view that the nominatives are not direct objects, but subjects, as their form and concord would suggest.

No special constraints are needed to regulate the interaction of inversion and Object Camouflage. Given the selective detransitivizing effect of inversion, inversion constructions cannot contain more direct verbal arguments than agreement

\footnotetext{
${ }^{12}$ This priority is also reflected in the fact that $(24 \mathrm{~b})$ is acceptable if second person šen is interpreted as the indirect object and masc'avlebels as the direct object.
} 
slots. As in earlier treatments of valence patterns or case and agreement properties, a correspondence-based analysis captures the intuition underlying traditional analyses, while preserving a simplified description of the morphological system, which constitutes one of the primary benefits of a traditional account.

\section{Conclusions and implications}

The main conclusions of this paper have been elaborated in the preceding discussion. The central claim is that inversion and passivization both involve a demotion in the mapping between thematic roles and grammatical relations, not in the association between grammatical relations and case and agreement processes. Inversion, in short, is not a 'quirky' valence pattern, but a non-canonical mapping of a prominent thematic role to a highly marked grammatical relation. A correspondencebased model helps to clarify the main objection to a quirky valence analysis. There is no principled reason why Georgian could not have dative subjects in inversion constructions. But there is no motivation for a dative subject analysis, given that any grammatical generalizations that refer to dative subjects can be expressed in terms of dative Proto-Agents, without the morphosyntactic disruption that dative subjects would cause. From a correspondence-based perspective, dative subjects are a symptom of 'overloading' the level surface grammatical analysis. By forcing generalizations that apply to Proto-Agents onto surface subjects, a quirky valence account produces a more heterogeneous class of subjects and complicates morphosyntactic patterns, with no compensating benefits.

\subsection{Grammatical relations}

At the same time, inversion highlights issues of relevance to correspondence-based models of argument structure, and to approaches to valence in general. One set of issues concerns the treatment of grammatical relations. Any framework must be able to distinguish indirect/secondary objects, however they choose to classify these elements. As Georgian shows, it must also be possible to ensure that at most one such element occurs in the argument structure of a verb in at least some languages. In addition, inversion constructions based on intransitive verbs confirm that subject-legislating constraints have no place in general theories of argument or clause structure. A Perfect form such as ucek'via 'danced' in (11b) governs just a surface indirect object, in violation of the Final 1 Law of RG (Perlmutter and Postal 1983b: 100), the Subject Condition of LFG (Bresnan and Kanerva 1989:28) and counterparts in other approaches. The existence of subjectless inversion constructions merely reinforce the evidence presented by Blevins (2003), among others, 
that subject-legislating constraints reflect what is at best a typological bias, and at worst a projection of the extreme subject-prominence of English.

The generic analyses and demotion rules can be reformulated in nearly any model of argument structure that makes available applicable notions of 'logical subject' and 'grammatical indirect object'. Somewhat surprisingly, given the attention devoted $t$ on valence alternations, the second of these prerequisites is stubbornly problematic in LFG. The initial formulations of LFG in Bresnan (1982a) do not include indirect objects among the core grammatical functions SUвJ(ЕСт), Овј(ЕСт), OBJ2 and OBL(IQUE). A given clause may contain at most one of each function, as a consequence of the Uniqueness condition, which stipulates that "in a given f-structure, a particular attribute may have at most one value" (Kaplan and Bresnan 1982:181). Of these functions, the 'secondary object function' овJ2 is the closest counterpart of a indirect object. But insofar as the introduction of овј2 serves largely to permit ditransitives to govern multiple objects in 'double object' constructions, овј2 differs from the class of dependents that are treated as indirect objects in traditional descriptions and as 3-terms in RG accounts.

Indirect objects are also excluded from later versions of LFG. To describe natural classes of grammatical functions, LMT accounts introduce a slightly revised inventory of functions, $\mathrm{SUBJ}, \mathrm{OBJ}, \mathrm{OBJ}_{\theta}$ and $\mathrm{OBL}_{\theta}$, defined jointly in terms of features and thematic role restrictions. As described in the chart in Table 10, the feature $[ \pm r$ (estricted) $]$ distinguishes 'thematically restricted' objects, $\left(\mathrm{OB}_{\theta}\right)$ and obliques $\left(\mathrm{OBL}_{\theta}\right)$ from subjects and thematically unrestricted objects. The feature [ \pm o(bjective) $]$ cross-classifies these functions by distinguishing objects from nonobjects. The main difference between the atomic grammatical functions in initial versions of LFG and the componential analyses in Table 19 is the replacement of the unitary grammatical functions овј2 and овL by "овј ${ }_{\theta}$ and $\mathrm{OBL}_{\theta}$ [which] represent families of relations indexed by semantic roles, with the $\theta$ subscript representing the semantic role associated with the argument" (Dalrymple 2001: 9f.).

$$
\begin{array}{llll}
\text { SUBJ } & {\left[\begin{array}{l}
-r \\
-o
\end{array}\right]} & \text { оBL }_{\theta} & {\left[\begin{array}{l}
+r \\
-o
\end{array}\right]} \\
\text { овJ } & {\left[\begin{array}{l}
-r \\
+o
\end{array}\right]} & \text { овJ }_{\theta} & {\left[\begin{array}{l}
+r \\
+o
\end{array}\right]}
\end{array}
$$

Figure 19: LMT feature analyses (Bresnan and Kanerva 1989:24)

Although the introduction of thematic indexing expands the inventory of grammatical functions, dependents with the properties of indirect objects in Georgian cannot be accommodated within the families of thematically restricted relations represented by $\mathrm{OBJ}_{\theta}$ or $\mathrm{oBL}_{\theta}$. No single thematically restricted object (or oblique) function captures the range of thematic interpretations traditionally associated with 
indirect objects. Hence there is no means of expressing the fact that inversion constructions allow exactly one indirect object, because thematically restricted objects with different restrictions count as different functions. As a result, neither the Uniqueness condition of Kaplan and Bresnan (1982) nor the subsequent FunctionArgument Biuniqueness condition of Bresnan and Kanerva (1989) is violated by an inversion construction in which the logical subject is realized by an OBJagent and the logical indirect object is realized by an OBJ goal. It would of course be possible to impose a constraint that allows at most one thematically restricted object in Georgian, but that would amount to treating distinct $\mathrm{OBJ}_{\theta}$ s as the 'same' function.

Substituting proto-roles for discrete roles will not improve matters, since the logical subject will correspond to a Proto-Agent role that is realized by an indirect object, while the logical indirect object will correspond to a Proto-Patient. The same difficulties arise if indirect objects are analyzed as thematically restricted obliques, or sometimes as thematically restricted objects and other times as thematically restricted obliques. It is because $\mathrm{OBJ}_{\theta}$ and $\mathrm{OBL}_{\theta}$ represent a 'families of functions' rather than single functions that there is no straightforward way to capture the generalization that inversion constructions allow a single indirect object.

The simplest way of integrating indirect objects into LMT is to import a basic insight from RG into the standard feature classification. RG accounts impose a fundamental distinction between term dependents, 1 (subject), 2 (direct object) and 3 (indirect object) and non-terms. Within LMT, this split corresponds to contrast between thematically unrestricted and thematically restricted functions. In addition, again as described in Table 10, RG distinguishes the nuclear terms 1 and 2 from all other dependents, including the non-nuclear term 3 . This distinction is represented in Table 12 by the feature $[ \pm l]$, which is negatively specified for subJ and овј and positively specified for all other functions. The addition of this feature permits the characterization of indirect objects as thematically unrestricted nonnuclear objects. Since this specification represents a single function rather than a family of functions, standard uniqueness conditions will ensure that at most one IOBJ can occur in an argument structure. This modification leaves the rest of the the LMT classification intact, including markedness relations between functions.

Augmenting the LMT classification avoids the need to reanalyze previous LMT analyses or to reexamine claims that indirect objects are absent from or unmotivated in other languages. An extension of the kind proposed in Table 12 accommodates indirect objects in languages, such as Georgian, where they are motivated. But it does not justify a general extrapolation from the Georgian evidence to the assumption that indirect objects are present in all languages. In languages that lack dependents of this type, the distinction between terms and nuclear terms will remain covert and componential analyses of LMT can revert to their original formulation. 


\begin{tabular}{cccc}
\hline Grammatical Function & $r($ estricted $)$ & o(bjective) & (ob)l(ique) \\
sUBJ & - & - & - \\
овJ & - & + & - \\
IОВ & - & + & + \\
овL $_{\theta}$ & + & - & + \\
овЈ $_{\theta}$ & + & + & + \\
\hline
\end{tabular}

Table 12: Expanded Grammatical Relation Inventory

\subsection{Thematic roles}

A separate set of issues concern the status of logical subjects. The present account follows Dowty (1991) in distinguishing just Proto-Agent and Proto-Patient roles, rather than the larger inventories recognized by accounts that follow in the Case Grammar tradition. However, for present purposes, the differences between these alternatives are inessential. Any generalizations that apply to Proto-Agents (or to actor 'macroroles' in the sense of van Valin (1990)) can be recast as applying to roles above a certain threshold in a thematic hierarchy. In either case, it is properties or entailments that distinguish the roles that are classified as logical subjects from those that are not. However, the notion of 'logical subject' relevant for inversion cannot be defined as "the most prominent semantic role of a predicator" (Bresnan 2001:307). The unergative cek'vavs 'dance' in (11) and the unaccusative ixat'eba 'be painted' in (13) are both intransitive verbs, associated with a single thematic role. This role is the only, and hence most prominent, role in the respective structures. Yet inversion treats the role associated with unergative cek'vavs, but not the role associated with unaccusative ixat'eba, as a logical subject. The traditional notion of logical subject may reconstructed in terms of the content of roles or proto-roles, or in terms of features (such as $[-o]$ or $[-r]$ ) that correlate with these properties. But logical subjects cannot be defined in terms of relative position in an argument structure.

As in the case of subject-legislating constraints, the Georgian evidence confirms a point that was already reasonably well established. Inversion discriminates between unaccusative and unergative verbs in much the same way that passivization does in most, if not all, languages. The RG literature presents an extended argument in support of the claim that 'no impersonal Passive clause in any language can be based on an unaccusative predicate' (Perlmutter and Postal 1984:107), as noted in Section 2.2. This pattern cannot be characterized in terms of any notion of logical subject based purely on prominence within an argument structure. Yet this is essentially the analysis assumed by LMT accounts that treat the passive as an "operation 
... which suppresses the highest thematic role in the lexical argument structure" (Bresnan and Kanerva 1989:26f.). An analysis of the passive that suppresses the highest thematic role of a predicate allows the passivization of passives and other types of unaccusative predicates. The idea that this consequence is desirable rests on the belief that passives of unaccusatives are attested. As discussed in Section 2.3, seems fairly clear that this belief is unfounded, and that putative examples of 'unaccusative passives' can be shown to be impersonal or evidential constructions. Hence the fact that unaccusative verbs do not undergo inversion in Georgian reinforces the case for distinguishing the notions 'logical subject' and 'highest thematic role'.

The present account also clarifies the status of grammatical features within LMT. The fact that a logical subject may be realized as an indirect object shows that logical subjects cannot be characterized as intrinsically 'nonobjective' functions, as suggested in a number of early LMT accounts (Bresnan and Kanerva 1989; Bresnan and Moshi 1990; Bresnan and Zaenen 1990). Instead, the $[-o]$ features assigned to logical subjects in these types of accounts serve to inhibit default mapping conventions from realizing logical subjects as objects. In inversion constructions, as in causatives (Ackerman and Moore 1999) and other types of grammatico-thematic 'demotions', logical subjects are realized as direct or indirect objects. Hence the features assigned to a role in an LMT analysis may restrict the default realizations of that role but do not determine the space of possible alternations in which the role may participate.

\section{References}

Ackerman, Farrell (1992). Complex predicates and morpholexical relatedness: Locative inversion in Hungarian. In Lexical matters (ed. I. A. Sag and A. Szabolcsi), pp. 55-83. CSLI, Stanford.

Ackerman, Farrell and Moore, John (1999). Syntagmatic and paradigmatic dimensions of causee encodings. Linguistics and Philosophy, 22, 1-44.

Ackerman, Farrell and Moore, John (2001). Proto-properties and Grammatical Encoding: A Correspondence Theory of Argument Selection. CSLI Publications.

Alsina, Alex (1996). The Role of Argument Structure in Grammar: Evidence from Romance. CSLI Publications, Stanford.

Anderson, Stephen R (1984). On representations in morphology: Case marking, agreement and inversion in Georgian. Natural Language and Linguistic Theory, 20, 157-218.

Anderson, Stephen R. (1992). A-Morphous Morphology. Cambridge University Press, Cambridge. 
Aronson, Howard I. (1990). Georgian: A Reading Grammar. Slavica, Columbus, $\mathrm{OH}$.

Baker, Mark, Johnson, Kyle, and Roberts, Ian (1989). Passive arguments raised. Linguistic Inquiry, 20, 219-251.

Blevins, James P. (2000). Markedness and agreement. Transactions of the Philological Society, 98(2), 233-62.

Blevins, James P (2003). Passives and impersonals. Journal of Linguistics, 39(3), 473-520.

Blevins, James P (2006). Word-based morphology. Journal of Linguistics, 42(3), 531-573.

Bloomfield, Leonard (1933). Language. University of Chicago Press, Chicago.

Bresnan, Joan (1982a). The Mental Representation of Grammatical Relations. MIT Press.

Bresnan, Joan (1982b). The passive in lexical theory. In The Mental Representation of Grammatical Relations, pp. 3-86. MIT Press, Cambridge, MA.

Bresnan, Joan (2001). Lexical-Functional Syntax. Blackwell, Oxford.

Bresnan, Joan, Asudeh, Ash, Toivonen, and Wechsler, Stephen (2016). LexicalFunctional Syntax (2nd edn). Wiley Blackwell, Oxford.

Bresnan, Joan and Kanerva, Jonni M. (1989). Locative inversion in Chicheŵa: A case study in factorization in grammar. Linguistic Inquiry, 20, 1-50.

Bresnan, Joan and Moshi, Lioba (1990). Object asymmetries in comparative Bantu syntax. Linguistic Inquiry, 21, 147-185.

Bresnan, Joan and Zaenen, Annie (1990). Deep unaccusativity in LFG. In Grammatical Relations: A Cross-Theoretical Perspective (ed. K. Dziwirek, P. Farrell, and E. Mejías-Bikandi), pp. 45-57. CSLI Publications, Stanford.

Chomsky, Noam (1981). Lectures on Government and Binding. Foris, Dordrecht.

Comrie, Bernard (1977). In defense of spontaneous demotion: The impersonal passive. In Syntax and Semantics 8: Grammatical Relations, pp. 47-58. Academic Press, New York.

Dalrymple, Mary (2001). Lexical Functional Grammar. Academic Press. 
Dowty, David (1991). Thematic proto-roles and argument selection. Language, 67, 547-619.

Dryer, Matthew S. (1986). Primary objects, secondary objects and antidative. Language, 62(808-845).

Fillmore, Charles (1968). The case for case. In Universals in Linguistic Theory (ed. E. Bach and R. T. Harms), pp. 1-88. Holt, Rinehart and Winston, New York.

Harris, Alice C. (1981). Georgian Syntax: A Study in Relational Grammar. Cambridge University Press, Cambridge.

Harris, Alice C. (1984). Inversion as a rule of universal grammar: Georgian evidence. In Studies in Relational Grammar 2 (ed. D. M. Perlmutter and C. Rosen), pp. 259-291. University of Chicago Press, Chicago.

Harris, Alice C. (1985). Diachronic Syntax: The Karvelian Case. Syntax and Semantics 18. Academic Press, New York.

Hewitt, B. G. (1995). Georgian: A Structural Reference Grammar. London Oriental and African Languages Library. John Benjamins, Amsterdam.

Jackendoff, Ray (1972). Semantic Interpretation in Generative Grammar. MIT Press, Cambridge.

Jakobson, Roman (1932). Zur Structur des russischen Verbums. Charisteria Guilelmo Mathesio Quinquagenario, 74-83.

Joppen-Hellwig, Sandra (2001). Verbklassen und Argumentlinking. Niemeyer, Tuübingen.

Kaplan, Ronald M. and Bresnan, Joan (1982). Lexical-functional grammar: A formal system for grammatical representation. In The Mental Representation of Grammatical Relations (ed. J. Bresnan), pp. 173-281. MIT Press, Cambridge.

Kibort, Anna (2003). The passive and passive-like constructions in English and Polish: A contrastive study with particular reference to impersonal constructions. Ph.D. thesis, University of Cambridge.

Manning, Christopher D. and Sag, Ivan A. (1999). Dissociations between argument structure and grammatical relations. In Lexical and Constructional Aspects of Linguistic Explanation (ed. G. Webelhuth, J.-P. Koenig, and A. Kathol), pp. 6378. CSLI, Stanford. 
Perlmutter, David M. (ed.) (1983). Studies in Relational Grammar 1. University of Chicago Press.

Perlmutter, David M. and Postal, Paul M. (1977). Toward a universal characterization of passivization. In Proceedings of the Third Annual Meeting of the Berkeley Linguistics Society. Reprinted in Perlmutter (1983), 3-29.

Perlmutter, David M. and Postal, Paul M. (1983a). The relational succession law. In Studies in Relational Grammar 1 (ed. D. M. Perlmutter), pp. 30-80. University of Chicago Press.

Perlmutter, David M. and Postal, Paul M. (1983b). Some proposed laws of basic clause structure. In Studies in Relational Grammar 1 (ed. D. M. Perlmutter), pp. 81-128. University of Chicago Press.

Perlmutter, David M. and Postal, Paul M. (1984). The 1-Advancement Exclusiveness law. In Studies in Relational Grammar 2 (ed. D. M. Perlmutter and C. G. Rosen), pp. 81-125. University of Chicago Press, Chicago.

Shore, Susannah (1988). On the so-called Finnish passive. Word, 39(3), 151-176.

Spraunienè, Birutė, Razanovaitè, Auksè, and Jasionytė, Erika (2015). Solving the puzzle of the Lithuanian passive. In Voice and Argument Structure in Baltic (ed. A. Holvoet and N. Nau), pp. 323-366. Benjamins, Amsterdam.

Stump, Gregory T. (2001). Inflectional Morphology: A Theory of Paradigm Structure. Cambridge University Press, Cambridge.

Timberlake, Alan (1982). The impersonal passive in Lithuanian. In Proceedings of the Eighth Annual Meeting of the Berkeley Linguistics Society, pp. 508-24.

Tommola, Hannu (1997). O supresive i ob ambipersonale. In Trudy po russkoj $i$ slavjanskoj filologii, Lingvistika, Novaja serija, pp. 173-87. Tartu Ülikooli Kirjastus, Tartu.

Torn-Leesik, Reeli (2016). An Investigation of Voice Constructions in Estonian. Ph.D. thesis, University of Tartu.

Tschenkéli, Kita (1958). Einführung in die georgische Sprache. Amirani Verlag, Zurich.

Tuite, Kevin (1998). Kartvelian Morphosyntax. Volume 12, Lincom Studies in Causasian Linguistics. Lincom Europa, Munich. 
van Valin, Robert D. (1990). Semantic parameters of split intransitivity. Language, 66, 221-260.

Wunderlich, Dieter (1997). A minimalist model of inflectional morphology. In The Role of Economy Principles in Linguistic Theory (ed. C. Wilder, H.-M. Gärtner, and M. Bierwisch), pp. 267-298. Akademie Verlag, Berlin.

Zaenen, Annie (1993). Unaccusativity in Dutch: An integrated approach. In Semantics and the Lexicon (ed. J. Pustejovsky), pp. 129-159. Kluwer Academic Publishers, Dordrecht. 